\title{
Reliability and Validity of the Second Edition of Self-Evaluated Soccer Performance Score
}

\author{
Takahiro Kawada $^{1,2}$, Hitomi Takeuchi ${ }^{3}$, Miyo Nakade $^{4}$, Fujiko Tsuji ${ }^{3}$, Akira Tamai $^{5}$, Hiroyuki Mizuno ${ }^{5}$, Tetsuo \\ Harada $^{3}$ \\ ${ }^{1}$ Center for Regional Collaboration, Kochi University, Kochi, Japan \\ ${ }^{2}$ Seikei University, Japan \\ ${ }^{3}$ Laboratory of Environmental Physiology, Graduate School of Integrated Arts and Sciences, Kochi, Japan \\ ${ }^{4}$ Faculty of Health and Nutrition, Tokai Gakuen University, Nagoya, Japan \\ ${ }^{5}$ Faculty of Politics Economy, Takushoku University, Tokyo, Japan \\ Correspondences: Tetsuo Harada, Laboratory of Environmental Physiology, Graduate School of Integrated Arts \\ and Sciences, Kochi University, Kochi 780-8520, Japan.
}

This questionnaire research project was supported financially from Fund for Local Corporation Activity from Kochi University (2014-2015: To Takahiro Kawada) and from JSPS fund: Kakenhi (Grant Number: JP 16K01871, 2016-2019, To Hitomi Takeuchi).

Received: October 1, 2017

Accepted: July 3, $2018 \quad$ Online Published: August 16, 2018

doi:10.5539/ijps.v10n3p29

URL: https://doi.org/10.5539/ijps.v10n3p29

\begin{abstract}
This study aims, first, to make the second edition of the self-evaluation of soccer performance scores which was edited based on the first version of the soccer performance scores (Kawada et al., 2016), and second, to examine the reliability and validity of the second version. Each of 16 questions was evaluated by one professional soccer coach who had an university assistant professor with A-class license for soccer supervisor which was officially given by Union for European Football Association (UEFA), a university soccer team coach and a university soccer team general manager. This second edition which was newly evaluated was administered to 111 university soccer club players who included starting members in the first class (A) team in December 2015. One hundred and eight answers (97.8\%) of 111 ones were used for the statistical analysis. After the validation analysis, this second edition can be estimated to be valuable for evaluating a valuable soccer performance scores.
\end{abstract}

Keywords: sports athletes, developing sports performance questionnaire, four components: technical, physical, communication and mental components

\section{Introduction}

\subsection{Development of Questionnaires in Relation with Several Characteristics in Sports Athletes}

Several questionnaires have been developed and validated on the sports related issue like as emotional intelligence (Laborde et al., 2014), social support in team playing (Coffee et al., 2017), physical activity (Santos-Silva et al., 2014), motor competence (Timler et al. , 2016), movement imagery ability (Martini et al., 2016), fatigue (Briout et al., 2007; Bricout, 2017). However, no evaluation has appear of the sports performance questionnaire which consists of multiple components of technique, physical power, mental ability and game strategy.

Laborde et al. (2014) validated a new questionnaire that was called the trait emotional intelligence questionnaire (TEIQue) for sports athletes. The first half of this study used a confirmatory factor analysis (CFA) to investigate if the original 4-factor structure of the TEIQue could be replicated in a sample of athletes. In addition, we explored the relationship was explored between trait emotional intelligence (trait EI) and the demographic variables age, sex, type of sport (individual vs. team), expertise, and years of training. The second half used a path analysis approach to explore if trait EI is related to performance satisfaction through stress appraisal and coping behaviors. This study showed that the TEIQue can be used with athletes and that trait EI is useful for understanding certain aspects of sports performance satisfaction. 
The validation of a new questionnaire of the Team-referent Availability of Social Support Questionnaire (the TASS-Q) was examined (Coffee et al., 2017). The first half of this study provided support for the factor structure of the TASS-Q comprising emotional, esteem, informational, and tangible dimensions. The second half provided partial evidence for the factor structure of the TASS-Q and evidence of the criterion-related validity of the measure, demonstrating that (a) team-referent esteem support was a positive predictor of collective efficacy, (b) support dimensions, collectively, explained significant variance in task cohesion dimensions, and (c) emotional support was a positive predictor of social cohesion (group integration social). The article provided initial evidence for the construct validity of the TASS-Q and demonstrates, for team-referent social support, the theoretical advantages of examining a multidimensional conceptualisation of perceived availability of social support.

The PAQ questionnaire (Physical Activity Questionnaire - Kowalski, Crocker, Donen) is a self-administered 7-day recall validated questionnaire that measures physical activity levels in young people (Santos-Silva et al., 2014). A final activity score is obtained (1 indicates low and 5 indicates high physical activity level). Despite the fact that a majority of the parents of allergic children stated that their child's disease was a barrier to physical activity, in our study there seems to be no difference between the level of physical activity of controlled asthmatic children and their healthy peers.

Timler et al. (2016) reported the development and evaluation of a self-report questionnaire (Adolescent Motor Competence Questionnaire; AMCQ). The final version of the AMCQ comprised 26 items scored using a 4 point Likert scale with a maximum score of 104. Analyses revealed the questionnaire has an acceptable internal consistency (0.902) and 7 day test-retest reliability (0.956). A moderate positive correlation between the AMCQ and the MAND of $0.491(\mathrm{p}<0.002)$ provides some evidence of concurrent validity. The development of the AMCQ was exploratory in nature and has the potential to be a reliable and valid tool for measuring motor competence in Australian adolescents.

Martini et al. (2016) showed that self-report questionnaires have been developed to assess movement imagery ability in adults, such as the Movement Imagery Questionnaire 3 (MIA-3). This process involved adaptation of the MIQ-3 via: i) cognitive interviewing with twenty children, ii) validation with 206 children by examining its factor structure via multi-trait-multi-method confirmatory factor analysis, and iii) examination of test-retest reliability with 23 children. In conclusion, findings support the use of the MIQ-C for examining movement imagery ability with children.

Bricout (2017) reported the validation of an English version of the Questionnaire of Fatigue for Sport Children 'QFSC'. In child and adolescent athletes, fatigue is an important symptom to consider cause it may be the first alarm system before the manifestation of an organic disorder. Prevention of fatigue in athletes is preferable to treatment. The training conditions, the professional medico-technical staff and the respect of child athletes are required to excel at the elite level. It might be possible to use the QFSC to detect the apparition of fatigue, to examine the effectiveness of various treatment(s) in helping athletes to recover from fatigue.

Systematic use of the Questionnaire for the QFES (in French: Questionnaire de fatigue de l'enfant) in parallel with medical consultations for children participating in sport may be an efficient tool to detect the early appearance of fatigue and may therefore be integrated in preventive guidance to protect children in sports practice (Bricout et al., 2007).

\subsection{Studies in Relation with Soccer Performance}

There have been numerous number of works on the soccer performance as follows: (1) Broadcasting video analysis (D'Orazio and Leo, 2010), (2) Soccer performance evaluation focused on agility (Bullock et al., 2012, Dardouri et al., 2014), (3) Speed and skill in soccer (Bullock et al., 2012), the quantification and monitoring of training load (Djaoui et al., 2017), (4) Soccer specific fatigue and performance (Greiga et al. 2007), (5) Measuring jumping performance of several kinds of athletes including soccer players (Kobal et al., 2017), and (6) Mathematical analysis on soccer games dynamics (Machado and Lopes, 2017).

\subsection{Broadcasting Video Analysis on Soccer Performance}

D'Orazio and Leo (2010) reported that, in their review paper, survey of soccer video analysis systems has been performed for different applications: video summarization, provision of augmented information, high-level analysis. Computer vision techniques have been adapted to be applicable in the challenging soccer context.

The tracking of players in monocular soccer videos was a challenging task because of numerous difficulties that can occur especially in TV broadcasts, such as camera motions, severe occlusion of players, or inhomogeneous lightning conditions (Herrmann et al., 2014). A new robust method was proposed for multi-player tracking, 
which was based on finding local maxima on a confidence map. This map represents an ensemble of visual evidences, such as colors of the team outfits, responses of a HOG human detector, and grass regions in images.

Soccer is world wide sport and has growth of demand for automatically analyzing matches and tactics (Manafifard et al., 2017). Since players have been on the focus of attention in soccer videos and they managed the entire game, player tracking has been fundamental to most soccer video analysis. An efficient implementation of the multiple hypothesis tracking algorithm by evaluating its usefulness in the context of soccer player tracking was introduced in this paper (Manafifard et al., 2017). Experimental results demonstrated that the efficiency and robustness of the algorithm.

\subsection{Soccer Performance Evaluation Focused on Agility, Speed and Skill in Soccer}

Bullock et al. (2012) tried to evaluate the effect of $45 \mathrm{~min}$ of soccer-specific exercise in the reactive motor skills test (RMST); a novel test which measures sprint, passing and reactive agility (RAT) performance. Soccer-specific exercise decreased sprint and reactive agility performance but improved technical skill performance on a novel, integrative and reliable test of soccer skill performance. Overall RMST performance time was largely unchanged.

The reliability and construct validity of straight sprint, agility, slalom dribble tests and skill index in young soccer players were examined (Dardouri et al., 2014). The three tests and Skill Index were reliable but only Agility Test, Slalom Dribble Test and Skill Index could discriminate between the levels of players' ability. They could be used for soccer-specific skills assessments and selection process of young soccer players.

\subsection{The Quantification and Monitoring of Training Load}

Djaoui et al. (2017) has reported their review paper and introduced the quantification and monitoring of training load (TL) which has been the topic of many scientific works in the last fifteen years. Training load monitoring helped coaches to individually prescribe, follow-up, analyze, adjust and program training sessions. Djaoui et al. (2017) reviewed a critical literature report regarding different physiological markers of training load monitoring, particularly in soccer. Heart rate (HR), HR variability (HRV) and biochemical variables (blood, urinary and hormonal variations) were analyzed, with a special focus on daily measures (before, during and after training) and monitoring throughout a whole season.

\subsection{Soccer Specific Fatigue and Performance}

There was no significant main effect for exercise duration in the stability index, suggesting that balance performance was maintained throughout the simulated match (Greiga et al. 2007). However, the mean deflection of the platform was significantly shifted toward anterior displacement during the last 15 min of each half. A change in balance strategy was evident during the latter stages of match-play, which may increase injury risk. It was recommended that soccer players perform proprioception training in the rested and exercised state to further develop neuromuscular control.

Polito et al. (2017) determined the main methods used to analyze the soccer players movement during games. Data were collected at three databases (PubMed, Medline and SPORT Discus) from 2010 to 2015, using the match terms: "perceived exertion" AND "fatigue" AND "soccer". The data criteria inclusion considered articles with match terms in titles and abstracts; studies purposes assessed central or peripheral fatigue in soccer players; psychological, physiological or psychophysiological variables; research design as a descriptive or experimental models. Palito et al. (2017) reported indirect and cheap methods to identify fatigue and psychophysiological changes during soccer matches and training session.

\subsection{Measuring Jumping Performance of Several Kinds of Athletes Including Soccer Players}

Kobal et al. (2017) compared the differences in vertical jumping abilities between top-level athletes from distinct sports specialties. Differences were found between the power group and all other groups in all tested variables (e.g., countermovement jump in power [48.31 $\pm 6.25 \mathrm{~cm}]$, soccer [40.95 $\pm 2.95 \mathrm{~cm}]$, tennis $[39.14 \pm 4.27 \mathrm{~cm}$ ] and endurance $[32.37 \pm 3.80 \mathrm{~cm}]$ athletes). There were no significant differences in reactive strength index among the soccer, tennis and endurance groups, although these groups presented lower reactive strength index than the power group. The power athletes performed better than all groups in jumping tests.

\subsection{Mathematical Analysis on Soccer Games Dynamics}

Machado and Lopes (2017) analyzed that the behavior of teams competing within soccer national leagues. The dissimilarities between teams have been measured using the match results at each round and that information fed a multidimensional scaling (MDS) algorithm for visualizing teams' performance. Data characterizing four European leagues during season 2014-2015 was adopted and processed using three distinct approaches. 


\subsection{A New Edition of Self-Evaluating Scores of Soccer Performance Which Includes Wide Variety of Elements}

Soccer game performance consists of wide variety of elements: various kind of estimations to measure the performance of soccer (Oe et al., 2013). Individual players have several kind of performance skills like as game control strategy (González-Víllora et al., 2015). Self-confidence on the soccer performance by players themselves seem to be very important for making their motivation for soccer game and also making their soccer performance in advance. However, there have been no self-evaluating scores on the soccer performance which was marked from a wide variety of elements especially from technical soccer skills, physical components like as stamina and fitness, mental toughness, and psychological strategies including game strategies. The objective of this study is to make and evaluate such a new and effective soccer performance scores index.

\section{Participants and Methods}

\subsection{Making the Second Edition of Self-Evaluated Questionnaire for Soccer Performance Scores}

The first edition of self-evaluated questionnaire for soccer performance was made by three under-graduate students who were university soccer club players. The first edition consisted of 11 questions and was used for the two studies on the intervention using a leaflet (Wada et al., 2012) which is to promote morning-typed life for sports athletes and using the recommendation of having milk at breakfast for university soccer club athletes (Kawada et al., 2016). The questionnaire on self-evaluation of soccer performance as the first edition (Kawada et al., 2016) consisted of the 11 components as follows: Question 1: Assessment of the present situation, Question 2: Visual field on playing, Question 3: Movement of foot, Question 4: Rudimentary mistake, Question 5: First touch, Question 6: Irritation on playing, Question 7: Running out of Stamina, Question 8: Injury on playing, Question 9: Body balance, Question 10: Precision of long kick, Question 11: Motivation for the practice. For the second edition, additional five components were added by one professional soccer coach who had university assistant professor with A-class license for soccer supervisor which was officially given by Union for European Football Association (UEFA), a university soccer team coach and a university soccer team general manager. The added four components were as follows: Question 12: Degree to understand the game strategy, Question 13: Precision of combination play, Question 14: Precision of playing to competitive players, Question 15: Ability on consciousness on the space, Question 16: Prediction ability (Table 1). For each of 16 questions, one of 6 selections was chosen and the selections were distributed from 1 (maximum, perfect) to 6 (not at all). 
Table 1. A questionnaire on the second edition of self-estimation index of soccer performance which consists of 16 components. Scores in each component distributed from 1 (the maximum implementation) through 2-5 (in the gradient of implementation in the middle, better to worse) to 6 (the minimum implementation). Total of the scores was distributed from 16 (the maximum) to 96 (the minimum).

Question 1: Assessment of the present situation, Question 2: Visual field on playing, Question 3: Movement of foot, Question 4: Rudimentary mistake, Question 5: First touch, Question 6: Irritation on playing, Question 7: Running out of Stamina, Question 8: Injury on playing, Question 9: Body balance, Question 10: Precision of long kick, Question 11: Motivation for the practice, Question 12: Degree to understand the game strategy, Question 13: Precision of combination play, Question 14: Precision of playing to competitive players (playing face to face), Question 15: Ability on consciousness on the space (heading ball and long ball), Question 16: Prediction ability (prediction ability for dangerous situation, covering play) (Kawada et al., 2017)

This questionnaire asks 16 questions of several aspects on your soccer performance. The answer can be in choice from 6 alternatives: 1: perfectly implemented (the maximum) through 2-5 (2: implemented, 3: relatively implemented, 4: relatively not implemented, 5: not implemented, to 6: not implemented at all (the minimum). Please make circle on the appropriate alternative in each question of 16 components.

(Performance has been better) (Performance has been worse)

\begin{tabular}{|c|c|c|c|c|c|c|}
\hline & 1 & 2 & 3 & 4 & 5 & 6 \\
\hline 1. Assessment of the present situation & (1) & (2) & (3) & (4) & (5) & (6) \\
\hline 2. Visual field on playing & (1) & (2) & (3) & (4) & (5) & (6) \\
\hline 3. Movement of foot & (1) & (2) & (3) & (4) & (5) & (6) \\
\hline 4. Rudimentary mistake & (1) & (2) & (3) & (4) & (5) & (6) \\
\hline 5. First touch & (1) & (2) & (3) & (4) & (5) & (6) \\
\hline 6. Irritation on playing & (1) & (2) & (3) & (4) & (5) & (6) \\
\hline 7. Running out of Stamina & (1) & (2) & (3) & (4) & (5) & (6) \\
\hline 8. Injury on playing & (1) & (2) & (3) & (4) & (5) & (6) \\
\hline 9. Body balance & (1) & (2) & (3) & (4) & (5) & (6) \\
\hline 10. Precision of long kick & (1) & (2) & (3) & (4) & (5) & (6) \\
\hline 11. Motivation for the practice & (1) & (2) & (3) & (4) & (5) & (6) \\
\hline 12. Degree to understand the game strategy & (1) & (2) & (3) & (4) & (5) & (6) \\
\hline 13. Precision of combination play & (1) & (2) & (3) & (4) & (5) & (6) \\
\hline 14. Precision of playing to competitive players & (1) & (2) & (3) & (4) & (5) & (6) \\
\hline 15. Ability on consciousness of the space & (1) & (2) & (3) & (4) & (5) & (6) \\
\hline $\begin{array}{l}\text { 16.Prediction ability (prediction ability for } \\
\text { dangerous situation) }\end{array}$ & (1) & (2) & (3) & (4) & (5) & (6) \\
\hline
\end{tabular}

The second version of self-evaluated questionnaire of soccer performance scores was administered to university soccer club players who were 111 men who include 11 starting members in A-team (top team) (Table 2). All of the 111 men who were university students with no marital status and basically dependent on parents financially, answered the questionnaire, whereas 108 athletes of the 111 answered it perfectly without the lack (97.3\%). The participants were aged on average 20.4 years old and ranged 18 yrs to 24 yrs. 
Table 2. Number of participants (\%)

\begin{tabular}{lllll}
\hline Age & & & \\
\hline$<20$ & 20 & 21 & $>21$ & In total
\end{tabular}

\begin{tabular}{|c|c|c|c|c|c|}
\hline $\begin{array}{l}\text { The other } \\
\text { members }\end{array}$ & $\begin{array}{l}33 \\
(33.6)\end{array}$ & $\begin{array}{l}22 \\
(22.4)\end{array}$ & $\begin{array}{l}22 \\
(22.4)\end{array}$ & $\begin{array}{l}21 \\
(21.4)\end{array}$ & $\begin{array}{l}98 \\
(100.0)\end{array}$ \\
\hline $\begin{array}{l}\text { Starting members } \\
\text { in the top (A } \\
\text { ranked) team }\end{array}$ & $\begin{array}{l}2 \\
(20)\end{array}$ & $\begin{array}{l}1 \\
(10.0)\end{array}$ & $\begin{array}{l}2 \\
(20.0)\end{array}$ & $\begin{array}{l}5 \\
(50.0)\end{array}$ & $\begin{array}{l}10 \\
(100.0)\end{array}$ \\
\hline
\end{tabular}

\section{Results}

\subsection{Reliability}

Fundamental and statistical analysis on the results of the 16 questions was shown in Table 3.

Although there were several answers which showed somewhat high degree of skew and kurtosis, all answers were within plus and minus 1 standard deviation from mean, and therefore neither ceiling effect nor bottom effect could be seen.

Table 3. Fundamental statistic analysis

\begin{tabular}{|c|c|c|c|c|c|c|}
\hline 16 components of the soccer performance questionnaire & Mini. & Max. & Mean & SD & Skew & Kurtosis \\
\hline 1. Assessment of the present situation & 2 & 6 & 3.41 & 0.928 & 0.527 & 0.003 \\
\hline 2. Visual field on playing & 2 & 6 & 3.46 & 0.932 & 0.357 & -0.152 \\
\hline 3. Movement of foot & 1 & 6 & 3.38 & 1.057 & 0.154 & -0.416 \\
\hline 4. Rudimentary mistake & 1 & 6 & 3.76 & 0.965 & -0.132 & 0.042 \\
\hline 5. First touch & 2 & 6 & 3.49 & 1.063 & 0.381 & -0.462 \\
\hline 6. Irritation on playing & 1 & 6 & 3.49 & 1.377 & -0.002 & -0.805 \\
\hline 7. Running out of Stamina & 1 & 6 & 3.64 & 1.384 & 0.029 & -0.896 \\
\hline 8. Injury on playing & 1 & 6 & 3.19 & 1.688 & 0.294 & -1.167 \\
\hline 9. Body balance & 2 & 6 & 3.42 & 1.12 & 0.456 & -0.489 \\
\hline 10. Precision of long kick & 2 & 6 & 3.49 & 1.046 & 0.150 & -0.768 \\
\hline 11. Motivation for the practice I & 1 & 6 & 2.70 & 1.255 & 0.870 & 0.319 \\
\hline 12. Degree to understand the game strategy & 1 & 6 & 3.11 & 1.062 & 0.490 & 0.471 \\
\hline 13. Precision of combination play & 1 & 6 & 3.34 & 0.856 & 0.550 & 1.061 \\
\hline 14. Precision of playing to competitive players & 1 & 6 & 3.39 & 1.058 & 0.033 & 0.096 \\
\hline 15. Ability on consciousness of the space & 1 & 6 & 3.24 & 1.26 & 0.219 & -0.539 \\
\hline $\begin{array}{l}\text { 16. Prediction ability (prediction ability for dangerous } \\
\text { situation) }\end{array}$ & 1 & 6 & 3.06 & 1.134 & 0.359 & -0.344 \\
\hline
\end{tabular}

Good-Poor analysis (G-P analysis) was performed (Table 3). The answers which were the maximum 25\% (more than the score 59) were significantly higher than those which were the minimum $25 \%$ (less than the score 48 ) as the result of T-test (Table 4) and the item discrimination ability was shown in the second edition. The value of the $\alpha$-value by Cronbach in the second edition was 0.81 which meant a high value of inner-constituency. 
Table 4. Good-Poor analysis (G-P analysis) and the ó-value by Cronbach

\begin{tabular}{|c|c|c|c|c|c|c|c|c|c|}
\hline & \multicolumn{8}{|c|}{ G-P analysis } & \multirow{3}{*}{$\begin{array}{l}\text { the } \\
\alpha \text {-value* } \\
\text { by } \\
\text { Cronbach } \\
\text { (total=0.81) }\end{array}$} \\
\hline & \multicolumn{2}{|c|}{$\begin{array}{l}\text { Maximum(upper } \\
25 \% \text { ) }\end{array}$} & \multicolumn{2}{|c|}{$\begin{array}{l}\text { Minimum(lower } \\
25 \% \text { ) }\end{array}$} & \multirow{2}{*}{ t-value } & \multirow{2}{*}{ df } & \multirow{2}{*}{$\mathrm{p}$-value } & \multirow{2}{*}{$\begin{array}{l}\text { Difference } \\
\text { in mean }\end{array}$} & \\
\hline & Mean & SD & Mean & SD & & & & & \\
\hline $\begin{array}{l}\text { 1. Assessment of the } \\
\text { present situation }\end{array}$ & 2.82 & 0.72 & 4.11 & 0.88 & -5.99 & 54.0 & 0 & -1.29 & 0.790 \\
\hline 2. Visual field on playing & 2.89 & 0.69 & 4.29 & 0.90 & -6.53 & 50.5 & 0 & -1.39 & 0.791 \\
\hline 3. Movement of foot & 2.71 & 0.94 & 4.07 & 0.94 & -5.41 & 54.0 & 0 & -1.36 & 0.794 \\
\hline 4. Rudimentary mistake & 3.04 & 0.88 & 4.21 & 0.92 & -4.90 & 54.0 & 0 & -1.18 & 0.795 \\
\hline 5. First touch & 2.86 & 1.01 & 4.21 & 0.92 & -5.27 & 54.0 & 0 & -1.36 & 0.795 \\
\hline 6. Irritation on playing & 3.11 & 1.37 & 4.07 & 1.49 & -2.52 & 54.0 & 0.015 & -0.96 & 0.817 \\
\hline 7. Running out of Stamina & 2.71 & 1.01 & 4.64 & 1.34 & -6.08 & 54.0 & 0 & -1.93 & 0.795 \\
\hline 8. Injury on playing & 2.36 & 1.34 & 3.96 & 1.82 & -3.77 & 49.7 & 0 & -1.61 & 0.830 \\
\hline 9. Body balance & 2.68 & 0.72 & 4.18 & 1.28 & -5.41 & 42.7 & 0 & -1.50 & 0.796 \\
\hline 10. Precision of long kick & 2.57 & 0.79 & 4.39 & 0.79 & -8.65 & 54.0 & 0 & -1.82 & 0.790 \\
\hline $\begin{array}{l}\text { 11. Motivation for the } \\
\text { practice }\end{array}$ & 1.96 & 0.84 & 3.04 & 1.11 & -4.09 & 54.0 & 0 & -1.07 & 0.816 \\
\hline $\begin{array}{l}\text { 12. Degree to understand } \\
\text { the game strategy }\end{array}$ & 2.5 & 0.75 & 3.79 & 1.13 & -5.01 & 46.7 & 0 & -1.29 & 0.796 \\
\hline $\begin{array}{l}\text { 13. Precision of } \\
\text { combination play }\end{array}$ & 2.79 & 0.69 & 4.04 & 0.92 & -5.75 & 49.9 & 0 & -1.25 & 0.790 \\
\hline $\begin{array}{l}\text { 14. Precision of playing to } \\
\text { competitive players }\end{array}$ & 2.79 & 0.96 & 3.79 & 1.17 & -3.51 & 54.0 & 0.001 & -1.00 & 0.804 \\
\hline $\begin{array}{l}\text { 15. Ability on } \\
\text { consciousness of the space }\end{array}$ & 2.36 & 0.91 & 4 & 1.33 & -5.38 & 54.0 & 0 & -1.64 & 0.798 \\
\hline $\begin{array}{l}\text { 16. Prediction ability } \\
\text { (prediction ability for } \\
\text { dangerous situation) }\end{array}$ & 2.39 & 0.74 & 3.89 & 1.26 & -5.45 & 43.6 & 0 & -1.50 & 0.795 \\
\hline
\end{tabular}

*: value on the rest 15 components without each one

\subsection{Validity}

The total scores of the second edition by the starting members of the top (A) team were significantly higher than those by the other university soccer club members (T-test, $t$-value $=3.94, \mathrm{df}=106.0, \mathrm{p}<0.001$ ). For each question of 16 components, there were significant difference in the scores of 7 components and a tendency of difference in other 3 components between the starting members and the other ones (Table 5). Therefore, validity was certified in the second edition of the soccer performance scores. 
Table 5. Comparison of answer to each component in the second version between the starting members (top players) and the other ones

\begin{tabular}{|c|c|c|c|c|c|c|c|}
\hline \multirow[b]{3}{*}{ 1. Assessment of the present situation } & \multicolumn{4}{|c|}{ Mean } & \multicolumn{3}{|l|}{ T-test } \\
\hline & \multicolumn{2}{|c|}{$\begin{array}{l}\text { Starting } \\
\text { member }\end{array}$} & \multicolumn{2}{|c|}{$\begin{array}{l}\text { The other } \\
\text { members }\end{array}$} & \multirow{2}{*}{$\begin{array}{c}t \text {-value } \\
2.21\end{array}$} & \multirow{2}{*}{$\begin{array}{l}\mathrm{df} \\
106.0\end{array}$} & \multirow{2}{*}{$\begin{array}{l}p \\
0.029\end{array}$} \\
\hline & 2.40 & $(1.26)$ & 3.48 & $(1.34)$ & & & \\
\hline 2. Visual field on playing & 2.60 & $(1.17)$ & 3.52 & $(1.36)$ & 2.04 & 106.0 & 0.044 \\
\hline 3. Movement of foot & 2.70 & $(1.70)$ & 3.38 & $(1.53)$ & 1.52 & 106.0 & 0.132 \\
\hline 4. Rudimentary mistake & 3.10 & $(2.02)$ & 3.93 & $(1.29)$ & 1.37 & 9.8 & 0.203 \\
\hline 5. First touch & 2.50 & $(1.78)$ & 3.54 & $(1.51)$ & 1.87 & 106.0 & 0.065 \\
\hline 6. Irritation on playing & 3.30 & $(1.89)$ & 3.49 & $(1.85)$ & 0.46 & 106.0 & 0.648 \\
\hline 7. Running out of Stamina & 2.50 & $(1.78)$ & 3.76 & $(1.84)$ & 2.04 & 106.0 & 0.044 \\
\hline 8. Injury on playing & 2.20 & $(1.75)$ & 3.22 & $(2.08)$ & 1.37 & 106.0 & 0.173 \\
\hline 9. Body balance & 1.80 & $(1.32)$ & 3.45 & $(1.59)$ & 2.80 & 106.0 & 0.006 \\
\hline 10. Precision of long kick & 1.90 & $(1.20)$ & 3.60 & $(1.55)$ & 3.29 & 106.0 & 0.001 \\
\hline 11. Motivation for the practice & 1.00 & $(0.00)$ & 2.52 & $(1.71)$ & 5.88 & 22.4 & 0.000 \\
\hline 12. Degree to understand the game strategy & 2.10 & $(1.20)$ & 3.06 & $(1.47)$ & 1.61 & 106.0 & 0.110 \\
\hline 13. Precision of combination play & 2.60 & $(1.17)$ & 3.38 & $(1.16)$ & 1.73 & 106.0 & 0.086 \\
\hline 14. Precision of playing to competitive players & 2.30 & $(1.16)$ & 3.44 & $(1.43)$ & 2.54 & 106.0 & 0.013 \\
\hline 15. Ability on consciousness of the space & 2.30 & $(1.64)$ & 3.27 & $(1.73)$ & 1.98 & 106.0 & 0.050 \\
\hline $\begin{array}{l}\text { 16. Prediction ability (prediction ability for } \\
\text { dangerous situation) }\end{array}$ & 2.20 & $(1.32)$ & 2.92 & $(1.64)$ & 1.34 & 106.0 & 0.184 \\
\hline In total & 43.1 & $(10.9)$ & 54.6 & $(8.62)$ & 3.94 & 106.0 & 0.000 \\
\hline
\end{tabular}

\subsection{Factor Analysis among 16 Components of the Second Edition}

Factor analysis among 16 components of the self-evaluated questionnaire was performed. The main-factor method was used with more than 1 fixed-value, more than $50 \%$ of accumulated ratio contribution. Four factors were extracted due to the method, and varimax rotation was done (Table 6). As the result, convergence occurred after 5 times of rotation. Due to the Table 6 which showed factor readings matrix after the rotation, the four components could be evaluated from the second edition of soccer performance scores. Namely, the four ones consist of (1) The fundamental technical ability (open-closed skills), (2) Movement ability which are physical ability, agility ability, judgment in the environment, (3) Strategy ability which are communication ability, judgment in the game, (4) Mental ability as a mental toughness. The factor analysis concluded that the second edition consisted of the four factors of technical phase, physical phase, tactical or strategy phase and mental phase. 
Table 6. Factor readings matrix after the rotation*

\begin{tabular}{lllll}
\hline & Factor 1 & Factor 2 & Factor 3 & Factor 4 \\
\hline Factor 1: Fundamental technical ability_- & & & & \\
1. Assessment of the present situation & 0.756 & 0.155 & 0.257 & 0.066 \\
2. Visual field on playing & 0.744 & 0.193 & 0.183 & 0.036 \\
4. Rudimentary mistake & 0.698 & 0.096 & 0.028 & 0.124 \\
5. First touch & 0.771 & 0.148 & -0.054 & 0.027 \\
10. Precision of long kick & 0.523 & 0.206 & 0.210 & 0.202 \\
\hline
\end{tabular}

Factor 2: Movement ability which are physical ability, agility ability, judgment in the environment

\begin{tabular}{lllll} 
3. Movement of foot & 0.150 & 0.472 & 0.172 & 0.358 \\
9. Body balance & 0.208 & 0.553 & -0.022 & 0.292 \\
14. Precision of playing to competitive players & 0.050 & 0.565 & 0.097 & 0.075 \\
15. Ability on consciousness of the space & 0.217 & 0.575 & 0.170 & -0.087 \\
$\begin{array}{l}\text { 16.Prediction ability (prediction ability for dangerous situation) } \\
\text { Factor 3: Strategy ability which are communication }\end{array}$ & 0.241 & 0.639 & 0.268 & -0.132 \\
\hline ability, judgment in the game & & & & \\
11. Motivation for the practice & -0.051 & 0.208 & 0.347 & 0.056 \\
12. Degree to understand the game strategy & 0.402 & 0.158 & 0.522 & -0.011 \\
13. Precision of combination play & 0.511 & 0.177 & 0.776 & 0.047 \\
\hline Factor 4: Mental ability as a mental toughness. & & & & 0.582 \\
6. Irritation on playing & 0.029 & -0.060 & 0.137 & 0.479 \\
7. Running out of Stamina & 0.247 & 0.197 & 0.144 & 0.549 \\
8. Injury on playing & 0.009 & 0.053 & -0.191 & \\
\hline
\end{tabular}

*The main-factor method was used with more than 1 fixed-value, more than $50 \%$ of accumulated ratio contribution. Four factors were extracted due to the method, and varimax rotation was done. As the result, convergence occurred after 5 times of rotation.

\section{Discussion}

The reliability and validity were performed on the newly made second-edition of self-evaluated questionnaire of soccer performance scores. The reliability and validity were shown in some extent after the analysis. The results of analysis showed that the second edition consisted of the four factors.

Based on the results of this study, four components of this questionnaire, namely technical, physical, mental and communication/strategy components, were evaluated and a high quality of performance questionnaire has been developed.

As the limitation of the second edition, this questionnaire is based on the self-evaluation. Therefore, the evaluation of performance as the performance standard could be changed due to the performance level of the players. However, there have been no tests of this newly made questionnaire on the athletes with wide variety of performance skills. Moreover, parts of the questionnaire can be modified for other sports kinds like as volley ball, rugby football, baseball and basketball so on. This new questionnaire may be resistant to athletes with wide variety of performances and several kind of sports, because this edition has a good valance of several factors not only on the technical and physical aspects but also mental issues and tactic ones. In the future, this new performance questionnaire could be applied to the other sports categories.

\section{Acknowledgements}

We would like to thank all participants and all staffs which helped this research projects for invaluable corporation and help. 


\section{References}

Bricout V.-A. (2017). Translation and linguistic validation of an English version of the Questionnaire of Fatigue for Sport Children 'QFSC'. Physiology \& Behavior, 171, 55-60. https://doi.org/10.1016/j.physbeh.2017.01.003

Bricout, V.-A., Charrier, I., Favre-Juvin, A. (2007). Use of the fatigue questionnaire (QFES) in child athletes for individual follow-up: two cases. Annales de réadaptation et de médecine physique, 50, 690-694. https://doi.org/10.1016/j.annrmp.2007.05.011

Bullock, W., Panchuk, D., Broatch, J., Christian, R., \& Stepto, N.K. (2012). An integrative test of agility, speed and skill in soccer: Effects of exercise. Journal of Science and Medicine in Sport, 15, 431-436. https://doi.org/10.1016/j.jsams.2012.03.002

Coffee, P., Freeman, P., \& Allen, M.S. (2017). The TASS-Q: The team-referent availability of social support questionnaire. Psychology of Sport and Exercise, 33, 55-65. https://doi.org/10.1016/j.psychsport.2017.08.003

Dardouri, W., Selmi, M.A., Sassi, R.H., Gharbi, R.H., Gharbi, Z., Rebhi, A., \& Moalla, W. (2014). Reliability and discriminative power of soccer-specific field tests and skill index in young soccer players. Science \& Sports, 29, 88-94. https://doi.org/10.1016/j.scispo.2013.06.004

Djaoui, L., Haddad, M., Chamari, K., \& Dellal, A. (2017). Monitoring training load and fatigue in soccer players with physiological markers. Physiology \& Behavior, $181, \quad 86-94$. https://doi.org/10.1016/j.physbeh.2017.09.004

D’Orazio, T., \& Leo, D. (2010). A review of vision-based systems for soccer video analysis. Pattern Recognition, 43, 2911-2926. https://doi.org/10.1016/j.patcog.2010.03.009

González-Víllora, S., Serra-Olivares, J., Pastor-Vicedo, J.C., \& da Costa, I.T. (2015). Review of the tactical evaluation tools for youth players, assessing the tactics in team sports: football. Springer Plus, 4, 663. https://doi.org/10.1186/s40064-015-1462-0

Greiga, M., \& Walker-Johnson, C. (2007). The influence of soccer-specific fatigue on functional stability. Physical Therapy in Sport, 8, 185-190. https://doi.org/10.1016/j.ptsp.2007.03.001

Herrmann, M., Hoernig, M., \& Radig, B. (2014). AASRI Conference on Sports Engineering and Computer Science (SECS 2014) - Online multi-player tracking in monocular Soccer videos. AASRI Procedia, 8, 30-37.

Kawada, T., Takamori, Y., Nakade, M., Tsuji, .F, Krejci, M., Noji, .T., Takeuchi, H., \& Harada, T. (2016). Effects of drinking cows' milk at breakfast in promoting sleep-health in Japanese university athletes. International Journal of Psychological Studies, 8, 154-163. https://doi.org/10.5539/ijps.v8n3p154

Kawada, T., Takeuchi, H., Nakade, M., Tsuji, F., Tamai, A., Mizuno, H., \& Harada, T. (2017). Social Jet Lag syndrome consisting of evening-typed life, lower social skill and worse soccer performance in university soccer club athletes. Sleep Disorders, submitted.

Kobal, R., Nakamura, F.Y., Kitamura, K., Cal Abad, C.C., Pereira, L.A. \& Loturco, I. (2017). Vertical and depth jumping performance in elite athletes from different sports specialties. Science \& Sports, in press. https://doi.org/10.1016/j.scispo.2017.01.007

Laborde, S., Dosseville, F., Guillén, F., \& Chávez, E. (2014). Validity of the trait emotional intelligence questionnaire in sports and its links with performance satisfaction. Psychology of Sport and Exercise, 15, 481-490. https://doi.org/10.1016/j.psychsport.2014.05.001

Machado, J.A.T., \& Lopes, A.M. (2017). Multidimensional scaling analysis of soccer dynamics. Applied Mathematical Modeling, 45, 462-452.

Manafifard, M., Ebadi, H., \& Moghaddam, H.A. (2017). Appearance-based multiple hypothesis tracking: Application to soccer broadcast videos analysis. Signal Processing: Image communication, 55, 157-170. https://doi.org/10.1016/j.image.2017.04.001

Martini, R., Carter, M.J., Yoxon, E., Cumming, J., \& Ste-Marie, D.M. (2016) Development and validation of the Movement Imagery Questionnaire for Children (MIQ-C). Psychology of Sport and Exercise, 22, $190-201$. https://doi.org/10.1016/j.psychsport.2015.08.008 
Oe, J., Ueda, T., Okihara, K., \& Ushi, S. (2013). Objective rating of game performance in soccer. Japan Journal of Physical Education, Health and Sports Science, 58, 731-736. (In Japanese) https://doi.org/10.5432/jjpehss.13019

Polito, L.F.T., Figueira Jr, A.J., Miranda, M.L.J., Chtourou, H., Miranda, J.M., \& Brandão, M.R.F.. (2017). Psychophysiological indicators of fatigue in soccer players: A systematic review. Science \& Sports, 32, 1-13. https://doi.org/10.1016/j.scispo.2016.09.003

Santos-Salva, R., Melo, C., Gonçalves, D., Coelho, J., \& Carvalho, F. (2014). Comparison between exercise performance in asthmatic children and healthy controls --- Physical Activity Questionnaire application. Revisa Portuguesa de Pneumologia, 20, 138-145. https://doi.org/10.1016/j.rppneu.2013.11.005

Timler, A., McIntyre, F., Cantell, C., Crawford, S., \& Hands, B. Development and evaluation of the psychometric properties of the Adolescent Motor Competence Questionnaire (AMCQ) for Adolescents. Research in Developmental Disabilities, 59, 127-137. https://doi.org/10.1016/j.ridd.2016.08.005

Wada, K., Itani, K., Nakade, M., Takeuchi, H., Noji, T., \& Harada, T. (2012). Intervention study using a leaflet entitled "Go to bed earlier! Get up earlier! Take nutritionally rich breakfast! for sports athletes" to promote soccer performance in university soccer club athletes. $37^{\text {th }}$ Annual Meeting of Japanese Sleep Research Society, 28-30 June 2012, Yokohama, Japan (in Japanese).

\section{Copyrights}

Copyright for this article is retained by the author(s), with first publication rights granted to the journal.

This is an open-access article distributed under the terms and conditions of the Creative Commons Attribution license (http://creativecommons.org/licenses/by/4.0/). 